\title{
Desafíos para la elaboración de una idea de libertad El aporte de la oboeditio fidei en Dei verbum 5
}

\author{
HADDY BELLO \\ Facultad de Teología \\ Pontificia Universidad Católica de Chile \\ hybello@uc.cl \\ (1) https://orcid.org/0000-0002-8504-789X
}

Resumen: La presente investigación tiene por objeto reflexionar en torno al problema de la libertad y destacar la centralidad de los aportes que el Vaticano II ha entregado y sigue ofreciendo 55 años después. En la revisión del texto conciliar se han incluido los procesos teológico-históricos que fueron constituyendo la reflexión actual sobre la oboeditio fidei. Es por esto que, a partir de la pregunta por la libertad, distinguiremos los principios o elementos que han influido en la elaboración y comprensión de este concepto. Entre las conclusiones podremos advertir el énfasis del Vaticano II de lograr un encuentro personal con la Revelación, la apuesta por el ser humano y el reconocimiento de su dignidad como hijo de Dios, el esfuerzo por humanizar las estructuras sociales, y la comprensión de la libertad cristiana como redescubrimiento de nuestra vocación humana.

Palabras claves: libertad, obediencia, fe, oboeditio fidei, Concilio, Vaticano II, antropología teológica.

Abstract: The present research pretends to reflect about the problem of freedom and highlight the implication of the contributions that the II Vatican Council keeps offering 55 years later. In the presentation of the conciliar text, we have included the theological-historical processes that resulted in the modern reflection on the oboeditio fidei. That is why, starting from the problem of freedom, we will distinguish the principles or elements that have influenced the development and understanding of this concept. Among the conclusions we will be able to underline how Vatican II emphasizes a personal encounter with the Revelation, the commitment to the human being and the recognition of his/her dignity as a child of God, the effort to humanize social structures, and the understanding of Christian freedom as a rediscovery of our human vocation.

Keywords: freedom, obedience, faith, oboeditio fidei, Council, Vatican II, theological anthropology. 


\section{INTRODUCCIÓN}

El momento actual se nos presenta como una historia de posibilidades y de libertad, conformada por aquellas decisiones o pequeñas libertades creadoras, que van sumando obras y acciones históricas. Hoy resuena con mayor fuerza un discurso de autosuficiencia, que presenta la idea de que para ser verdaderamente libre, se debe creer solo aquello que la razón permita, depositando la confianza fuertemente en la técnica y en la ciencia. En muchos ambientes, la razón es considerada como lo más propio del progreso, y, por tanto, para ser libre la persona tiene el imperioso deber de desprenderse de todas aquellas ataduras-creencias, ritos, arquetipos, etc.- que puedan ser lastre para la conciencia o que puedan reportar el riesgo de oscurecer el conocimiento científico o adormecer la razón. Éste es el conocido proceso de desmitologización o "desencantamiento de las imágenes del mundo" del cual hablaban Weber y Nietzsche ${ }^{1}$.

La gran tentación al respecto fue "pensar que se protegen plenamente nuestros derechos personales solo cuando nos vemos libres de toda norma de la ley divina”" Según el filósofo canadiense Charles Taylor, las transformaciones sociales a causa de la modernidad podrían describirse "en términos de una pérdida de creencias y lealtades tradicionales" ${ }^{3}$. La desmitologización fue tan dura que en algunas corrientes todo se redujo a la persona. Tal fue el caso del existencialismo humanista de Sartre quien, en su obra El existencialismo es un humanismo (1946), escribió: "El ser humano es el único que no solo es tal como él se concibe, sino tal como él se quiere [...]; la persona no es otra cosa que lo que ella se hace. Éste es el primer principio del existencialismo" ${ }^{4}$. Tomando este texto, podremos entender con más claridad por qué, si volcamos nuestra mirada sobre la iglesia, la jerarquía, los mandamientos o cualquier elemento que constituya norma, este hombre -arrojado a su existencia-

\footnotetext{
Cf. J. Beriain, "Modernidad y sistemas de creencias”, en G. Vattimo y otros, En torno a la posmodernidad (Anthropos Editorial, Barcelona $\left.{ }^{2} 2003\right) 131$.

2 Concilio Vaticano II, Constitución pastoral sobre la Iglesia en el mundo actual: Gaudium et Spes (Biblioteca de Autores Cristianos, Madrid 22000) núm. 41.

3 Ch. TAYlor, "Dos Teorías sobre la Modernidad”, en Relaciones internacionales (Revista académica cuatrimestral de publicación electrónica. Universidad Autónoma de Madrid 7; Madrid 2008) 2.

4 J.P. Sartre, El existencialismo es un humanismo (Pequeños Grandes Ensayos 1; Universidad Nacional Autónoma de México, Distrito Federal 2006) 28-29.
} 
verá en ellos un obstáculo para comprender su propia vida, pues los considerará simplemente como imposición externa que inhibe lo que para él es lo más auténtico de la realización del ser "como él se quiere". Podemos agregar también que la tentación de una mentalidad cientificista exacerbada ha generado una incapacidad de tolerar como verdadero aquello que no pueda ser explicado por ella, experimentando un miedo irracional frente a la muerte, al sufrimiento y a todo misterio natural o sobrenatural que no pueda ser alcanzado por la razón técnica. Esta incapacidad hace que toda religación o sentimiento religioso propio de la vida espiritual de la persona sea asumido y abordado por las ciencias humanistas, la psicología, la sociología o, como sucede actualmente, por las técnicas de meditación y relajación provenientes de la filosofía oriental. Esta tendencia no responde necesariamente a un olvido de Dios, sino a un querer prescindir o liberarse -como ya habíamos dicho- de toda atadura posible. El ser humano quiere vivir "como él se quiere".

Finalmente, ampliando un poco la mirada, podemos advertir que la opción por una vida en coherencia con estas formas promueve la construcción de una estructura social profundamente individualista, ordenada bajo el alero de la autosatisfacción. Esta forma de vida responde a las propias inclinaciones y se mantiene disociada de toda responsabilidad social connatural al ejercicio de dicha libertad. Tampoco aquí hay espacio para escuchar al otro, ni para asociar mi libertad a la de nadie más. En suma, podríamos representar este pensamiento bajo el siguiente cántico:

Dios está arriba, el hombre abajo;

Dios es Dios, el hombre es el hombre;

Cada cual a lo suyo, cada cual en su casa ${ }^{5}$.

Ese "cada cual en su casa", podríamos pensar, alberga la diversidad de corrientes ideológicas que están influyendo en los discursos de la modernidad y que hasta hoy determinan las prácticas económicas, políticas, sociales y espirituales de la actividad humana de este siglo. Esta diversidad hace necesario repensar qué es lo más genuino en el ser humano, y desde allí, entender la libertad como acción liberadora, cuya guía es la fe (no la religiosidad) y nos permite ser lo que somos.

5 Cf. M. EliADE, Tratado de historia de las religiones: morfología y dialéctica de lo sagrado (Eds. Cristiandad, Madrid $\left.{ }^{3} 2000\right) 126$. 


\section{Preguntas a partir de la libertad y una propuesta de respuesta a PARTIR DE LA OBOEDITIO FIDEI EN DEI VERBUM 5}

La presente investigación pretende ser una contribución para quienes, en el deseo de conocer y entender a Dios, se preguntan por la acción divina en la historia y en la propia historia: ¿En qué medida Dios interviene en el mundo? ¿Lo que experimento diariamente, es voluntad de Dios o es producto del uso de las libertades de cada individuo? Si bien es posible no ser capaces de resolver estas preguntas fundamentales de manera íntegra, no podemos obviar que son cuestionamientos concretos que son elementales para la reflexión teológica y pastoral, hoy más que nunca, tiempos de tempestad, en donde el misterio de la libertad nos ayuda a comprender a su vez el misterio de Dios.

Una sana comprensión de la relación entre Dios y el ser humano puede contribuir además con una re-comprensión de nuestras dinámicas relacionales como Iglesia. Para ello, sugiero comenzar con una breve reflexión a partir del "Hagamos al ser humano a nuestra imagen" de Gn 1, 26. Si asentimos a la idea que hemos sido creados a imagen y semejanza divina, no podemos pensar que el modo de relacionarnos con Dios sea el de dos extraños, ni mucho menos el de los esclavos frente a su señor, no podemos creer en una relación desde el temor, la atrición o el sometimiento. Es más, si recordamos las palabras de san Ireneo: "La gloria de Dios es el hombre viviente, y la vida del hombre es la visión de Dios"6, vemos la edificación de un vínculo que supera con creces los límites de una relación servil o proficiente entre ambos. Pero, si el lazo entre Dios y el hombre es tan evidente, ¿por qué a tantos y a tantas este Dios PadreCreador les es desconocido? ¿Qué es aquello que dificulta la escucha y la obediencia a un Padre bondadoso? Una clave para entrar en una comprensión del misterio de la libertad que se da en la relación entre Dios y el hombre, propongo hacerlo mediante la propuesta de la oboeditio fidei, es decir, de la obediencia de la fe como capacidad del hombre de escuchar la voluntad de Dios y de dar respuesta al diálogo que éste le propone existencial y radicalmente. La medida de dicha respuesta determinará -a fin de cuentas- con qué hondura podrá Dios hacerse presente en la vida de aquella persona que libremente lo acoge o lo rechaza.

$6 \quad$ Ireneo de Lyon, Adversus haereses (IV 20, 7): Gloria enim Dei vivens homo, vita autem hominis visio Dei. 
La fecundidad de la oboeditio fidei se realiza en el diálogo de tres elementos: la fe, la razón y la libertad. De estos, el que nos plantea un mayor desafío es precisamente el último: ¿qué entendemos por libertad? Si bien, la enseñanza del Catecismo de la Iglesia Católica nos propone una definición básica:

El poder, radicado en la razón y en la voluntad, de obrar o de no obrar, de hacer esto o aquello, de ejecutar así por sí mismo acciones deliberadas. Por el libre arbitrio cada uno dispone de sí mismo. [...] Hasta que no llega a encontrarse definitivamente con su bien último que es Dios, la libertad implica la posibilidad de elegir entre el bien y el mal ${ }^{7}$.

Esta no es suficiente para profundizar sobre el misterio. Hay que distinguir, como Agustín de Hipona ${ }^{8}$, entre la capacidad de elección enunciada por el Catecismo, llamándola liberum arbitrium (libertad menor o exterior), de otra que se juzga como superior: libertas (libertad mayor o interior), y que es ponderada por él como la verdadera libertad, pues, a diferencia de la primera, ésta reside en el interior del hombre y, por tanto, lo constituye desde lo más íntimo de sí. De esta manera, la libertad más auténtica "no quiere decir que puedo hacer lo que quiera; en el sentido pleno de la palabra, significa más bien que debo llegar a ser lo que soy. Me presta la capacidad de ser yo mismo, de lograr mi identidad". Sobre esa libertas nos avocaremos en este trabajo y desarrollaremos la cuestión de la libertad cristiana en la oboeditio fidei.

Catecismo de la Iglesia Católica (Editorial San Pablo, Santa Fe de Bogotá 2000) núm. 1731-1732.

8 Si bien ambos términos (liberum arbitrium y libertas) se han usado de forma indistinta, se ha visto que Agustín hace una distinción semántica al hablar de libertas minor y de libertas maior cuando expresa que -luego del pecado- la verdadera libertad nos viene de la gracia (cf. Contra secundam Iuliani responsionem imperfectum opus, liber unus, 12, 35, PL 44), o sostiene que la libertad perfecta es aquella que implica la desideranda necessitas de querer el bien y de no poder no quererlo (cf. De correptione et gratia, liber quintus, 61, PL 45). Ver en A. Trapè, S. Agostino: Introduzione alla dottrina della grazia (Collana Studi Agostiniani 4, tomo II; Città Nuova, Roma 1990) 79.

9 K. Rahner, citado en J. L. Ruíz de la PeÑa, Imagen de Dios: antropología teológica fundamental (Colección Presencia Teológica 49; Sal Terrae, Santander 1988) 187. 


\section{El APORTE DE LA OBOEDITIO FIDEI}

La constitución dogmática Dei verbum aportará el fundamento para esta reflexión, pues, en breves líneas, descubre el tesoro del misterio de la libertad presente en la dinámica de Dios que se revela y del hombre que responde: "Cuando Dios revela, el hombre tiene que prestar la obediencia de la $f e$ "10. Este número -cuyo texto completo veremos en el siguiente punto- compendia lúcidamente la compleja experiencia que toda persona atraviesa cuando se enfrenta a la Revelación desde su ser histórico (personal, comunitario, etc.), y al mismo tiempo le exige una respuesta que le haga tomar posición frente a ella; es decir, puede aceptarla con la obediencia, o rechazarla con la desobediencia, pero nunca habrá espacio para una auténtica indiferencia, pues la estructura de la persona humana no soporta por mucho tiempo un estado de inestabilidad, ambigüedad o estoicismo, ya que naturalmente tiende hacia lo estable. Entonces, si nos preguntamos: ¿Cómo ayuda la obediencia de la fe al problema de la libertad cristiana?, podemos decir que ella encausa y da sentido al homenaje total que la persona ofrece, iluminando -con el auxilio del Espíritu Santo- el vínculo entre naturaleza y gracia. De este modo, cuando se afirma que el hombre "tiene que prestar la obediencia de la fe", no se presenta el acto de creer como un movimiento coercitivo, externo o desvinculado de la persona creyente, todo lo contrario, la obediencia de la fe supone un camino de interioridad ya recorrido de la mano de Dios, un habitus que nos permite participar en la naturaleza divina ${ }^{11}$. En otras palabras, una experiencia que implica conversión y transforma a cada hombre y a cada mujer en testigo y testiga ${ }^{12}$ de la manifestación histórica de Dios.

\section{Orange, Trento y Vaticano I. Elementos y antecedentes de la TEOLOGÍA DE LA OBOEDITIO FIDEI}

Siguiendo nuestro camino, revisaremos los antecedentes que permitieron al Concilio Vaticano II llegar a la elaboración de una teología

10 Concilio Vaticano II, Constitución dogmática sobre la divina Revelación: Dei verbum (Biblioteca de Autores Cristianos, Madrid 22000) núm. 5: Deo revelanti praestanda est oboeditio fidei.

11 Cf. A. MeIs, Gracia desbordante y Teología Práctica. Apuntes (Santiago 2011) 133.

12 Categoría que mejor auto-implica al sujeto en su discurso, de modo que no solo habla sobre algo o alguien, sino que vive aquello que expresa. 
sobre la oboeditio fidei en Dei verbum 5: en primer lugar, el Sínodo de Orange II, que aportó con su omnibus suavitatem in consentiendo et credendo veritati; y luego el Concilio Vaticano I, con su declaración plenum revelanti Deo intellectus et voluntatis obsequium. Ambas, se distinguen en Dei verbum 5:

Cuando Dios revela, el hombre tiene que prestar la obediencia de la fe (cf. Rm 16, 26; comp. con Rm 1, 5; 2 Co 10, 5-6). Por la fe el hombre se entrega entera y libremente a Dios, le ofrece "el homenaje total de su entendimiento y voluntad"13, asintiendo libremente a lo que Dios revela. Para dar esta respuesta de la fe es necesaria la gracia de Dios, que se adelanta y nos ayuda, junto con el auxilio interior del Espíritu Santo, que mueve el corazón, lo dirige a Dios, abre los ojos de la mente y concede "a todos gusto en aceptar y creer la verdad" 14 . Para que el hombre pueda comprender cada vez más profundamente la inteligencia de la revelación, el Espíritu Santo perfecciona constantemente la fe con sus dones ${ }^{15}$.

Además de los aportes mencionados, propongo adicionalmente un tercero, que a pesar de no estar señalado explícitamente en DV 5, está cronológica y teológicamente situado entre Orange II y Vaticano I, por lo que también deberá ser examinado: el Concilio de Trento.

\subsection{Sinodo II de Orange (año 526-530)}

Este sínodo, celebrado con el propósito de esclarecer y fortalecer la doctrina de la gracia frente al pelagianismo y al semipelagianismo, tuvo su arranque prácticamente un siglo antes. La clave de la disputa la encontramos en la propuesta del monje Pelagio: "La naturaleza del hombre, tal cual es, es capaz por su propio conocimiento y especialmente por su libre voluntad de evitar el pecado y hacer méritos para el cielo"16.

13 Concilio Vaticano I, Dei filius, cap. 3 (DH 3008).

14 Sínodo de Orange II, can. 7 (DH 377). Concilio Vaticano I, Dei filius, cap. 3 (DH 3010).

15 Concilio Vaticano II, Dei verbum, 5: Deo revelanti praestanda est oboeditio fidei, qua homo se totum libere Deo committit "plenum revelanti Deo intellectus et voluntatis obsequium" praestando et voluntarie revelationi ab Eo datae assentiendo. Quae fides ut praebeatur, opus est praeveniente et adiuvante gratia Dei et internis Spiritus Sancti auxiliis, qui cor moveat et in Deum convertat, mentis oculos aperiat, et det «omnibus suavitatem in consentiendo et credendo veritati». Quo vero profundior usque evadat revelationis intelligentia, idem Spiritus Sanctus fidem iugiter per dona sua perficit. (DH 4205).

16 J. LorTz, Historia de la Iglesia, I (Eds. Cristiandad, Madrid 1982) 177. 
Esto significa que, mediante la voluntad natural (liberum arbitrium), el hombre es capaz de elegir, de entre las múltiples posibilidades que se le ofrecen, aquello que es conveniente para su bien. De manera que prácticamente todo lo que existe en la obra de salvación es acción humana, excepto tres acontecimientos: la creación del ser humano; la Revelación, que culmina en Jesucristo; y la predicación de la Iglesia ${ }^{17}$.

Ante el embate pelagianista, Orange quiso salvaguardar la primacía de la gracia de Dios y la necesidad de la fe para que el hombre pudiese, en el ejercicio de su libertad, descubrir aquellas realidades, obras y opciones que son favorables para su felicidad, es decir, para la santidad o la salud de la vida eterna, aseverando con firmeza:

Si alguno afirma que por la fuerza de la naturaleza se puede pensar, como convienen, o elegir algún bien que toca a la salud de la vida eterna, o consentir a la saludable, es decir, evangélica predicación, sin la iluminación o inspiración del Espíritu Santo (absque illuminatione et inspiratione Spiritus Sancti), que da a todos suavidad en el consentir y creer en la verdad (qui dat omnibus suavitatem in consentiendo et credendo veritati), es engañado de espíritu herético, por no entender la voz de Dios que dice en el Evangelio: "Sin mí nada podéis hacer" $(\text { Jn } 15,5)^{18}$.

En esta illuminatio, presentado en el canon 7 , se reconoce un movimiento inicial de la gracia, que es el que posibilita la libertad y la oboeditio en el hombre. Es el papel del Espíritu Santo como anticipador que defenderá el Vaticano II en Dei verbum 5, al confirmar: Spiritus Sancti auxiliis, qui cor moveat et in Deum convertat, mentis oculos aperiat, et det "omnibus suavitatem in consentiendo et credendo veritati".

Podemos ver cómo en Orange -mediante la acción del Espíritu Santo- se expone un concepto de fe mucho más complejo de lo que se estimaba, es decir, fe no como un mero sentimiento interior inspirado por Dios, que hace al hombre creer en él automáticamente; tampoco una simple luz anímica o espiritual que viene a iluminar la oscuridad de la razón científica; sino más bien una capacidad de escuchar (ob-audire) a Dios. ¿A qué me refiero cuando menciono esta capacidad de escucha? No digo que esto es lo que Orange deseaba establecer, pero es inevitable interpretar las palabras del sínodo en el siguiente sentido: si es el Espíritu

17 Cf. S. Silva, Teología Fundamental. Apuntes de Clase (Santiago 2005) 192.

18 Sínodo de Orange II, can. 7 (DH 377). 
Santo quien nos guía hacia el sumo bien, hacia Dios mismo, es entonces Dios -en primera persona- quien nos habla al corazón. Pero no todos escuchan o pueden escuchar su voz ${ }^{19}$, lo hacen únicamente aquellos a quienes él se los permite, pues es un don. Por tanto, la fe puede ser propuesta como la capacidad, dada por Dios al hombre, de poder escuchar su voz. De este modo, la oboeditio fidei sería la concreción de esta capacidad de ob-audire. Este sonido -suave pero potente a la vez-suena, se hace audible en el Espíritu Santo; y se hace posible y visible en Cristo.

\subsection{Concilio de Trento (años 1545-1563)}

En Trento distinguíamos un tercer aporte que ha apoyado las elaboraciones teológicas de la doctrina de la gracia y de la oboeditio fidei. A modo de contexto, podemos decir que, a diferencia de los Concilios de la Edad Media -que más bien se ocuparon de reglamentar el orden de la sociedad cristiana-, Trento se dedicó a la corrección y defensa de la fe católica ante los cuestionamientos que los padres reformadores y la cultura secularizada habían alzado contra algunas malas prácticas que se estaban produciendo al interior de la Iglesia ${ }^{20}$. Con este Concilio se formaliza por primera vez

la alternancia entre temas de "fe" [...]; y los problemas de "reforma" [...]. El binomio fides et mores adquiere de este modo una autoridad que se conservará durante toda la época de la Contrarreforma, convirtiéndose en el esquema rígido de clasificación de los temas eclesiales ${ }^{21}$,

lo que inevitablemente instalaba muchas interrogantes sobre cómo vivir la fe, la razón y la libertad, a partir de la experiencia vital de la Revelación. A pesar de que este binomio produjo la enunciación formal de un tipo de discurso teológico anti, podemos considerar la antropología tridentina como un aporte para la Iglesia, ya que,

en contra del pesimismo radical de los teólogos de la Reforma, preservó, con el libre albedrío, lo esencial del humanismo. Y con la

\footnotetext{
19 Imposibilidad causada por la voluntad humana herida por el pecado original. Por tanto, Dios, a través de su Espíritu, la guía y la lleva hacia él. Cf. S. SiLva, Teología Fundamental, 196.

20 Cf. G. Alberigo, Historia de los concilios ecuménicos (Ediciones Sígueme, Salamanca 1993) 12.

21 G. Alberigo, Historia de los concilios ecuménicos, 13.
} 
doctrina de la justificación mantuvo una forma de cooperación del hombre a la obra de su propia salvación ${ }^{22}$.

Lamentablemente,

la impresión de equilibrio que pueden dar estos textos conciliares es en parte engañosa, como habría de demostrar la historia sucesiva, tanto en lo que se refería a la ambigüedad sobre las relaciones entre la gracia divina y la libertad del hombre $[. .$.$] como en lo relativo a un$ desplazamiento hacia un moralismo puramente secular, que valorizaría sobre todo el siglo XVIII ${ }^{23}$.

Sin embargo, en Trento se instaló un aspecto importante en relación con la persona del Espíritu Santo, que concernirá a la antropología teológica y, sin duda, será un antecedente importante para la teología expuesta en Dei verbum 5: "Para dar esta respuesta de la fe es necesaria la gracia de Dios, que se adelanta y nos ayuda (praeveniente et adiuvante gratia Dei)". Esto nos lleva a recordar la controversia sobre el initium fidei entre Agustín y Pelagio que ahora vuelve a desarrollarse en el "Decreto sobre la justificación":

Al tocar Dios el corazón del hombre por la iluminación del actuar del Espíritu Santo, ni puede decirse que el hombre mismo no hace nada en absoluto al recibir aquella inspiración, puesto que puede también rechazarla; ni tampoco, sin la gracia de Dios, puede moverse, por su libre voluntad, a ser justo delante de él ${ }^{24}$.

Entre todo lo consignado en las sesiones conciliares respecto a la justificación, distingo este número como el más lúcido para nuestra confrontación con DV 5 y para definir la estrecha relación entre fe, gracia y libertad, puesto que lleva a un nivel más íntimo y personal la decisión, tanto de Dios como posteriormente del hombre, de iniciar un diálogo libre y fecundo, posibilitado por el Espíritu Santo. Hay una armonía entre la gracia de Dios y la libertad del hombre que se explicita más adelante en el mismo número (DH 1525), cuando dice: "Confesamos que somos prevenidos de la gracia de Dios", es decir, la gracia precede, anticipa, previene; por tanto, de ella proviene el primer llamado y es ella quien ayuda al hombre a convertirse a Dios asintiendo y cooperando libremente con

\footnotetext{
22 G. Alberigo, Historia de los concilios ecuménicos, 294.

23 G. Alberigo, Historia de los concilios ecuménicos, 294.

24 Concilio de Trento, Decreto sobre la Justificación, capítulo 5 (DH 1525).
} 
la gracia ${ }^{25}$. Esto significa que el initium fidei no se actualiza indefinidamente, sino que -como dice Balthasar- es "aquel primer conocimiento que el hombre recibe en sí, solo como un relámpago. Después vienen tinieblas y acaso una noche cada vez más oscura" ${ }^{26}$ que, sin el intelecto y la auténtica voluntad de acoger la gracia por parte del hombre, no dará muchos frutos, ni alcanzará permanencia a lo largo del tiempo.

Contrario a esto estaba Lutero, quien pensaba que a causa de la instalación del pecado en el género humano no era el hombre quien podía decidirse hacia Dios, sino que era Dios quien se decidía por el hombre ${ }^{27}$. Es decir, no era posible que en el corazón del hombre hubiese alguna voluntad disponible para Dios, pues estaba completamente dañado a causa del pecado de Adán. Pero Trento rápidamente condenó el error ${ }^{28}$.

En resumen, Trento reconoce claramente que cuando hablamos de la fe o de la gracia nos encontramos frente a un don divino (al Espíritu Santo) que se "adelanta y ayuda" al ser humano a realizar dicha experiencia de fe, lo fortalece en su decisión, lo mueve al amor y al bien, pero no lo obliga a realizarlo. Es el sello indeleble de la libertad de Dios que se le comunica íntegramente al ser humano, haciéndolo responsable de sus propios actos. Este reconocimiento de la primacía de la libertad dado por el Concilio, como ya sabemos, no logró zanjar el problema, y los siglos posteriores "de reflexión postridentina significaron un periodo de sombras, pese al resplandor de la Contrarreforma y la Época barroca"29. El tema resurgirá en el próximo Concilio.

\subsection{Concilio Vaticano I (1869-1870)}

1300 años desde la celebración del Sínodo de Orange y más de 300 años desde la clausura de Trento, todavía prosiguen los inconvenientes

25 Cf. Concilio de Trento, Decreto sobre la Justificación, capítulo 5: eidem gratiae libere assentiendo et cooperando.

26 H. U. von Balthasar, "El camino de acceso a la realidad de Dios", en Mysterium Salutis, II (Ediciones Cristiandad, Madrid $\left.{ }^{2} 1977\right) 39$.

27 Cf. A. MeIs, Antropología Teológica. Acercamientos a la paradoja del hombre (Ediciones Universidad Católica de Chile, Santiago $\left.{ }^{2} 2001\right) 393$.

28 Cf. Concilio de Trento, Decreto sobre la Justificación, cánones 3-5 (DH 1553-1555).

29 A. MeIs, Antropología Teológica, 403. No hemos profundizado en las doctrinas de Bayo y Jansenio, porque hacerlo implicaría desviarnos de nuestro tema, obligándonos a desentrañar otras problemáticas externas al propósito de la presente tesis. 
para identificar los límites de la acción de la gracia en la capacidad humana -el ejercicio de la razón natural- para el conocimiento de Dios. Peor aún, por miedo a no tener la lucidez necesaria para integrar correctamente en el discurso teológico el modo en el cual conviven en el hombre los vestigios de una humanidad herida por el pecado y su ser justificado por la gracia de Cristo, se evitaba reconocer que el deseo de lo bueno procedía de Dios y no de una libertad puramente natural ${ }^{30}$. Teniendo en cuenta esta dificultad, entre otras, el problema de la relación fe y razón prácticamente pasó a un segundo plano (digamos que el principal interés era resolver el cuestionamiento de la infalibilidad del Papa). Aun así, el Concilio Vaticano I volvió a entrar en materia intentando dar una respuesta más sólida y completa -una suerte de apología de la fe ante la razón ${ }^{31}$ - en buena parte para zanjar tanto el problema del fideísmo y el semirracionalismo iniciado por Bautain ${ }^{32}$, como el del racionalismo, ya condenado por Pío IX en 1864 mediante el Syllabus. De este modo, fue a través de cuatro sesiones solemnes que se concretó el rumbo de este Concilio. Entre ellas, la tercera (24 de abril de 1870), estableció la Constitución dogmática sobre la fe católica, Dei filius, que entre sus cuatro capítulos incluyó uno dedicado exclusivamente al tema de la fe (cap. 3):

Dependiendo el hombre totalmente de Dios como su creador y señor, y estando la razón humana enteramente sujeta (totus dependeat) a la verdad increada, cuando Dios revela (revelanti), estamos obligados a prestarle por la fe (fide) plena obediencia (plenum obsequium) de entendimiento y voluntad ${ }^{33}$.

30 Incluso, desde Trento se pensaba que "los escollos que había que evitar eran los de dar demasiada importancia o demasiado poca a la libertad del hombre pecador respecto a la iniciativa, que ninguno negaba, de Dios que salva y justifica” (G. ALBERIGO, Historia de los concilios ecuménicos, 294).

31 Sistema que distinguía tres cualidades: 1) Un carácter fuertemente antideísta; 2) Un intento de establecer el hecho de la revelación divina sin tener presente el sentido de su contenido; 3) La pretensión de dar una demostración racional rigurosa. Cf. S. Pí́-Ninot, La teología fundamental. Dar razón de la esperanza (Agape 7; Ediciones Secretariado Trinitario, Salamanca ${ }^{5}$ 2002) 38.

32 Entre las corrientes más influyentes están: el fideísmo de L. E. Bautain; el tradicionalismo de A. Bonnetty; el semirracionalismo de J. Hermes; el semirracionalismo de A. Günther quien, junto con Hermes, fue el principal exponente del semirracionalismo alemán del siglo xix. Cf. J. Collantes, La fe de la Iglesia Católica. Las ideas de los hombres en los documentos doctrinales del magisterio (Biblioteca de Autores Cristianos, Madrid 1983) 30-42.

33 Concilio Vaticano I, Dei Filius, canon 1 (DH 3008). 
Con esta enunciación ${ }^{34}$, el Vaticano I "entraba en lo más vivo de la confrontación con la cultura moderna" ${ }^{35}$, pues no solo ahondaba en la relación entre fe y razón, sino que además parecía que quería ir más allá: El hombre no solo debía creer en Dios cuando Éste se le revelaba (estamos obligados a prestarle plena obediencia), sino que además dependía totalmente de él.

A pesar de los esfuerzos realizados por los padres conciliares, éste capítulo no fue capaz de disminuir la sensación de insatisfacción de la civilización moderna frente a la articulación de la fe y la razón respecto a la libertad del hombre. Estimo que podríamos atribuir este descontento a la imposibilidad antropocéntrica de admitir, en primer lugar, la gratuidad del don de la fe por parte de Dios. Los hombres se preguntaban: ¿Cómo es posible que tener o no tener algo (en este caso, tener fe), no pudiera depender de ningún mérito humano? Esto sí que les parecía una potestad sumamente injusta. En segundo lugar, venía la dependencia de la razón a la Revelación. Pareciera que la impotencia del ser humano frente a un Dios a quien no puede dominar, poseer o conocer, si él no se lo permite, fuese algo negativo o pernicioso contra el ser humano. No se ha aceptado plenamente que somos creaturas y, por tanto, como tales, es lógico que en Dios creador resida un poder real sobre nosotros, poder que no es injusto ni perverso, sino legítimo. En el fondo, la existencia de un tipo de conocimiento o realidad revelada, a la cual la razón no puede acceder por sí sola, los hacía interrogarse: ¿Hasta qué punto es válido afirmar como ciencia un conocimiento teológico imposible de evaluar bajo el método científico?

De cara a estos cuestionamientos, en el texto previamente expuesto sobre Dei filius presentamos tres ideas claves para comprender y favorecer la naturaleza de la oboeditio fidei:

\subsubsection{El totus dependeat}

En aquel tiempo, la dependencia a Dios ha sido considerada por muchos como un golpe a la autonomía del ser humano ¿Por qué produce tanto conflicto el totus dependeat? ¿Acaso el niño antes de nacer no depende totalmente de su madre para la mantención de su salud?

34 Que más adelante retomará el Vaticano II, incluyendo otros elementos del capítulo 3 de la Dei filius, especialmente de los cánones 2-5 (cf. DH 3008-3010).

35 G. Alberigo, Historia de los concilios ecuménicos, 324. 
¿No sigue dependiendo de ella una vez nacido? ¿Es esta dependencia un problema o impedimento para el desarrollo intelectual, espiritual o profesional de ese niño? En una relación natural y sana, definitivamente no. Aún en la madurez y autonomía de sus hijos, los padres siguen unidos a ellos por un lazo indeleble. Algo análogo sucede con Dios, cuyo lazo no es sanguíneo, sino ontológico. Esto nos señala que totus dependeat no significa estar subordinado a una autoridad, como si se estuviera bajo algún tipo de esclavitud; ni tampoco refiere a la situación de quien no puede valerse por sí mismo, porque el ser humano, dotado de razón, entendimiento y voluntad, es libre para ejercerlos. Dependeat proviene del verbo dependere, cuya significación -actualmente en desuso- es "colgar o pender de alguna cosa"36, por lo tanto, nuestra vida (de)pende de Dios, en cuanto Él nos ha dado el ser y sostiene nuestra existencia. No somos simplemente microorganismos biológicos evolucionados, como planteaba Darwin ${ }^{37}$, sino que somos hijos de Dios, pues en Dios mismo por medio de Jesucristo se nos ha comunicado la vida divina, haciéndonos hijos, y si hijos, también herederos (cf. Ga 4, 7).

\subsubsection{El plenum obsequium fide}

Aceptar la filiación ya comentada, es reconocer la sacralidad de la vida humana a causa del vínculo con Dios, lo que al mismo tiempo nos permite afirmar en el hombre la posibilidad -siempre gratuita- de un tipo de conocimiento anterior al puramente racional, un conocimiento desde la gracia o, en otras palabras, un "primer conocimiento del amor a partir del acto con que ha sido despertado y convertido [el hombre] en un espíritu cognoscente y amante" ${ }^{38}$. La respuesta a este primer conocimiento (fidei assensus) no es "un movimiento ciego del alma" ${ }^{39}$, sino el don de Dios que anticipa toda acción humana sin atentar contra el ejercicio libre del intelecto y la voluntad, pues requiere de ellos para realizarse y desplegarse. Por otra parte, para resguardar la presencia real $-\mathrm{y}$ no simbólica- de la libertad en el hombre ante la Revelación que le exige una toma de posición, quisiera rescatar el concepto de obsequium que

36 Real Academia Española, Diccionario de la lengua española (Espasa Calpe S. A., Madrid $\left.{ }^{21} 1992\right)$ 482, voz: "depender".

37 Cf. Ch. Darwin, El origen del hombre y la selección en relación al sexo (Ediciones Ibéricas, Madrid ${ }^{2}$ 1966) 12.

38 H. U. Von Balthasar, "El camino de acceso a la realidad de Dios", 38.

39 Cf. DH 3010. 
emplea el Vaticano I y que posteriormente adoptará el Vaticano II en DV 5. La palabra obsequium, puede utilizarse en la acción de obsequiar como "agasajar a uno con atenciones, servicios o regalos" (en un cumplimiento en el amor) ${ }^{40}$, o como sustantivo de rendimiento (obediencia), que es el modo en que ambos concilios la utilizan. Por tanto, podríamos asociar la obediencia de la fe con aquel "cumplimiento en el amor" de aquella vida que se me ha revelado, un cumplimiento obediente que necesita realizarse en el hombre mediante todas sus capacidades (anímicas, físicas, psíquicas, espirituales, afectivas, etc.). Por tanto, hacer el ejercicio de encauzar todo el hombre, todo de sí hacia un mismo punto, hacia Dios, claramente además del auxilio de la gracia, requiere de un deseo plenamente libre por parte de la persona humana en todas sus dimensiones, y sería casi imposible reducirlo a un acto meramente racionalista o puramente fideísta ${ }^{41}$. En suma, no basta la obediencia a secas para amar a Dios, pues "el acto de creer, se sitúa en el ámbito antropológico de las opciones honestas y responsables que toda persona realiza o puede contentarse con realizar" ${ }^{42}$. Para amar a Dios es necesaria la fe de un corazón atravesado por el amor divino, inspirado por el Espíritu Santo y encarnado con el Hijo.

\subsubsection{El revelanti Deo}

Debe quedar claro que asumir la presencia de la libertad en el $o b-$ sequium, implica asumir paralelamente la posibilidad de una respuesta negativa del hombre ante la revelación de Dios. Lamentablemente, en la Constitución Dei filius, el contenido de la revelación de Dios se define en términos objetivos y externos (externa revelationis suae argumenta), sin ninguna referencia a una experiencia inter-personal y vital. Pero buscando en otros estudios relativos al tema, hemos encontrado que la palabra revelare puede entenderse en dos momentos simultáneos:

40 En ocasiones puede confundirse con el adjetivo "obsequioso" (del latín obsequiosus), que significa "rendido, cortesano y dispuesto a hacer la voluntad de otro" (Real Academia Española, Diccionario de la lengua española, 1036).

41 Contra el fideísmo y el racionalismo, Dei filius rescata la complementariedad de las relaciones entre y razón: "Hay un doble orden de conocimiento, distinto no solo por su principio, sino también por su objeto; por su principio, primeramente, porque en uno conocemos por razón natural, y en otro por fe divina." (DH 3015; también DH 3017).

42 Cf. S. Pié-Ninot, La teología fundamental, 214-215. 
un quitar el velo, es decir, "descubrir lo que estaba cubierto, sacar a luz lo que estaba escondido, hacer público, hacer manifiesto, de forma que quede abierto y patente" 43 (en nuestro caso, cuando revelare se predica de Dios: revelanti Deo, se da por supuesto que éste es un Dios oculto que rompe voluntariamente su silencio para manifestarse al hombre); $y$ una apertura, donde aquello -o aquél- no solo se deja ver, sino también se deja conocer, es decir, no solo se muestra, sino que también afecta al hombre y se deja afectar por él ${ }^{44}$.

Dei filius no cierra el camino a ulteriores profundizaciones teológicas sobre la relación entre Revelación, dogma y conciencia personal ${ }^{45}$, más bien, nos desafía a pensar la fe desde un movimiento compuesto entre acción de Dios (en la persona, en la creación, en la Iglesia) y respuesta libre del ser humano a dicha acción. Respuesta que por supuesto requiere de una fe madurada, es decir, sustentada por argumentos racionales que muestren que es razonable creer (equilibrio necesario contra el fideísmo y el racionalismo), siendo esta opción creyente una adhesión libre y no el resultado de una demostración racional necesitante, pues sigue siendo obra de la gracia de $\operatorname{Dios}^{46}$.

Mediante los elementos expuestos, podemos ver que el desafío para el Concilio Vaticano II, respecto a la relación entre fe y razón en torno a la libertad, será articular una síntesis entre el optimismo pelagiano (donde la esperanza está radicada en los méritos humanos para alcanzar la salvación), y el pesimismo protestante (en el que solo la fe salva, sin que la praxis cristiana tenga una incidencia relevante en el desenlace escatológico).

\subsection{Concilio Vaticano II. El primer impulso}

La visión de convocar a un nuevo Concilio tuvo su génesis en los proyectos de dos pontífices precedentes a Juan XXIII: Pío XI y Pío XII. El primero, a inicios de su pontificado (1922-1939), abrigó la idea de llamar a un Concilio que fuera continuación del Vaticano I, una suerte

43 H. FrIEs, "El concepto católico de revelación”, en Mysterium Salutis, I (Ediciones Cristiandad, Madrid 21974) 211.

44 "La Revelación incluye ambas cosas y las abarca: revelar como acto y facultad, y revelar como cosa revelada" (H. Fries, "El concepto católico de revelación", 211).

45 Cf. A. Zambarbieri, Los concilios del Vaticano (Teología Siglo XXI 19; San Pablo, Madrid 1996) 98.

46 Cf. S. SiLva, Teología Fundamental, 205. 
de reanudación del trabajo conciliar iniciado por Pío IX y "que buscase un remedio oportuno a la actual decadencia provocada por las grandes perturbaciones de la humanidad" 47 . Tal fue su esfuerzo, que en 1923 consultó a todos los obispos ${ }^{48}$, pero a pesar de la positiva recepción de su propuesta, tuvo que abandonarla temporalmente, pues tenía otras preocupaciones más urgentes que atender (entre ellas, la búsqueda de una solución permanente a la llamada cuestión romana $)^{49}$, lo que finalmente le obligó a postergar el proyecto conciliar, confiando en que éste pudiera ser retomado prontamente por su sucesor. Así, bajo el pontificado de Pío XII (1939-1958), se puso en marcha una reflexión más enérgica y decidida para elaborar el Concilio. Esta vez la iniciativa fue encabezada por Ernesto Ruffini (arzobispo de Palermo) y Alfredo Ottaviani (en ese entonces, asesor del Santo Oficio). Para ellos, el Vaticano II "debía ser, ante todo, un Concilio doctrinal que aportara seguridades y certezas" 50 . Esta idea, aun cuando marchaba velozmente, reportaba una profunda complejidad: llegar a acuerdo para determinar qué temas abordar y qué métodos utilizar para alcanzar las "seguridades y certezas" necesarias para los nuevos tiempos. Tampoco se lograba consenso sobre qué tipo de Concilio se deseaba celebrar. El gran número de sesiones y reuniones requeridas volvieron a dificultar llevar a puerto el anuncio de un Vaticano II para este pontificado y el mismísimo Pío XII llegó a la conclusión de que los tiempos no eran propicios ${ }^{51}$ para un Concilio largo, especialmente con las dificultades y retos que éste ocasionaba. Nuevamente el proyecto conciliar debió ser postergado, pero el Espíritu Santo no tardó en suscitar -algunos meses después- un inesperado suceso: El 25 de enero de 1959, Juan XXIII anunció su decisión de convocar un nuevo concilio $^{52}$. Éste fue "un toque inesperado al alma"53, una inspiración que no debe leerse como un acto aislado del pontífice, sino como acción de

Pío XI, Encíclica Ubi arcano, 23 de diciembre de 1922 (AAS 14 [1922] 691-692).

48 Cf. K. Schatz, Los concilios ecuménicos (Editorial Trotta, Madrid 1999) 254.

49 Cf. L. M. DE SAN MarTín, Juan XXIII. Retrato eclesiológico (Herder, Barcelona 1998) 243.

50 L. M. de San Martín, Juan XXIII, 244.

51 Cf. L. M. DE San MarTín, Juan XXIII, 246.

52 G. Alberigo, Historia de los concilios ecuménicos, 338.

53 JuAn XXIII, Gaudet Mater Ecclesia. Discurso para la inauguración del Concilio Vaticano II, 11 de octubre de 1962 (AAS 54 [1962], vol. LIV, 788). 
disponibilidad a la voluntad de $\operatorname{Dios}^{54}$, que lo hizo capaz de acoger el proyecto concebido por Pío XI, de leer los signos de los tiempos y de responder al sensus fidei que se manifestaba. Debía ser un Concilio que no condenara herejías, sino que se ocupara de los desafíos pastorales ${ }^{55}$ Con esto, diversas reacciones se desencadenaron y, si bien, en un primer momento, no obtuvo una acogida muy entusiasta de sus más cercanos, logró producir el gozo y la esperanza en gran parte del pueblo cristiano. La fuerza alcanzada fue producto de la esperanza que el mundo cristiano albergaba en la Iglesia que, como madre y maestra, pudiera abrirse ante las necesidades de una sociedad en cambio y acompañar a sus hijos en medio de los grandes movimientos intelectuales que prometían -y ya ejercían- una revolución ${ }^{56}$ sobre la cultura, la economía, la religión y la política. De esta manera el Concilio concretó claramente el proceso de reconciliación con la modernidad, dejando atrás el infortunado movimiento iniciado con el Syllabus ${ }^{57}$.

3.4.1. Los esquemas de Dei verbum y su teología de la oboeditio fidei en DV 5

Sobre el itinerario realizado por Dei Verbum, se dice que cada uno de los esquemas transparentó el espíritu de cada sesión conciliar: primero, un período de sondeo; luego, uno de encauzamiento; siguiéndole un espíritu más crítico; y finalmente, uno de madurez ${ }^{58}$. De hecho, los cuatro esquemas "coinciden exactamente con los cuatro períodos del concilio. La preparación de esos esquemas, con los períodos de inter-sesión

54 Cf. Y. Congar, Le Concile de Vatican II: son église, peuple de Dieu et Corps du Christ (Théologie Historique 71; Beauchesne Éditeur, Paris 1984) 46.

55 El Concilio creó una nueva denominación para sus documentos: 'Constitución pastoral' (el caso de Gaudium et Spes). Cf. S. Silva, Teología Fundamental, 214.

56 Revolución que el Papa no vio con malos ojos: "En el presente momento histórico, la Providencia nos está llevando a un nuevo orden de relaciones humanas que, por obra misma de los hombres pero más aún por encima de sus mismas intenciones, se encaminan al cumplimiento de planes superiores e inesperados" (JUAN XXIII, Gaudet Mater Ecclesia (AAS 54 [1962], vol. LIV, 789)).

57 "Colección de errores modernos preparada por el 'Santo Oficio' [...]. Se trataba de escritos claramente antirracionalistas y, en política, antiliberales” (S. SiLva, Teología Fundamental, 200).

58 Cf. G. Ruiz, "Historia de la Constitución «Dei Verbum»", en L. AlOnSO-SchÖKEL y otros, Concilio Vaticano II: Comentarios a la Constitución Dei Verbum sobre la divina revelación (Biblioteca de Autores Cristianos, Madrid 1969) 76. 
y preparación del concilio; su discusión [a excepción del $\mathrm{II}^{\circ} \mathrm{E}$ ], con las sesiones del mismo concilio" ${ }^{59}$. El primer esquema $\left(\mathrm{I}^{\circ} \mathrm{E}\right)$ De fontibus revelationis $^{60}$, no fue recibido con entusiasmo ${ }^{61}$. Por su título ya producía malestar. Si bien podemos designar la Escritura y la Tradición como fuentes de la Revelación, no excluyen otras posibilidades que tenga Dios de manifestarse o de permitir su conocimiento ${ }^{62}$. Se le criticaba también un "estilo docente y escolástico, ajeno a preocupaciones pastorales y ecuménicas, y la falta de perspectiva en los temas tratados" ${ }^{3}$, además de no abordar con precisión el tema de la Revelación, en cuanto no definía su naturaleza ni el modo de salvación que con Dios se manifestaba, ni mucho menos entraba en la realidad de Cristo como culmen y síntesis de esa teofanía ${ }^{64}$. Tampoco fue satisfactorio el tratamiento del tema de la fe, puesto que no logró una profundización en base a las ideas sobre la oboeditio fidei establecidas en los Concilios de Trento y Vaticano I. La reformulación del De fontibus revelationis desembocó en una nueva y atrayente propuesta para el segundo esquema ( $\left.\mathrm{II}^{\circ} \mathrm{E}\right)$ : De divina revelatione (título que se mantuvo para el tercer y el cuarto esquema). Con esta variación, los padres conciliares quisieron manifestar el cambio de énfasis en la formulación teológica del Vaticano II con relación a la Revelación, es decir, ya no era un examen crítico-apologético de los problemas en torno a la Escritura y a la Tradición, sino claramente un estudio sobre la naturaleza de la Revelación, o sea, más que un cambio de estructura era un cambio de contenido ${ }^{65}$. El tercer esquema $\left(\mathrm{III}^{\circ} \mathrm{E}\right)$, no recibió mayores modificaciones en su mensaje y los cambios en la estructura fueron menores. En referencia a nuestro texto (DV 5), hay dos

59 G. Ruiz, "Historia de la Constitución «Dei Verbum»", 46.

60 Constaba de cinco capítulos: I. La doble fuente de la Revelación; II. Inspiración e inerrancia en las Sagradas Escrituras; III. Antiguo Testamento; IV. Nuevo Testamento; V. Las Sagradas Escrituras en la Iglesia.

61 Según el registro de votaciones que aparece en L. AlONSO-SCHÖKEL y otros, Concilio Vaticano II: Comentarios a la Constitución Dei Verbum sobre la divina revelación (Biblioteca de Autores Cristianos, Madrid 1969) 86; en las votaciones conciliares sobre el "Esquema I", de los 2.209 votantes: 1.368 estaban a favor, 822 en contra, y 19 votaron nulo. Sufragio que arrojó la más alta cifra de desaprobación en todo el proceso de la Dei verbum.

62 Cf. O. Semmelroth - M. Zerwick, El Concilio Vaticano II y la "Dei Verbum" (Cuestiones Actuales 11; Ediciones Paulinas, Florida [Arg.] 1968) 9.

63 G. Ruiz, "Historia de la Constitución «Dei Verbum»", 51.

64 Cf. G. Ruiz, "Historia de la Constitución «Dei Verbum»", 51.

65 Cf. G. Ruiz, "Historia de la Constitución «Dei Verbum»", 55. 
intervenciones específicas: primero "se cambia el orden de los números 5 y 6, pues parece más normal colocar la respuesta de la fe a la Revelación antes de hablar de otras verdades accesibles a la razón" ${ }^{66}$, y luego, se insiste en que el número 5 desarrolle "una descripción de la fe más bíblica y personalista" ${ }^{\prime}$. Finalmente, el cuarto esquema $\left(\mathrm{IV}^{\circ} \mathrm{E}\right)$, era ya el reflejo de un trabajo prósperamente interiorizado por quienes habían trabajado durante varios años en las Comisiones ${ }^{68}$. Respecto a nuestro texto (número 5), hay únicamente un leve "intercambio de sujeto y complemento, para expresar que es la Revelación (no la fe), el objeto principal de dicho número" ${ }^{69}$. Es Dios quien en la manifestación libre y entrañable de su amor -en su Hijo, el $\Lambda$ óyos- pone en movimiento y sostiene la vida del hombre, y es Dios en su Santo Espíritu quien suscita la fe como posibilidad de diálogo y comunión, permitiendo (auxiliando) una respuesta concreta a dicha Revelación. Presentamos un esquema con la evolución de la oboeditio fidei en Dei verbum $5^{70}$ :

66 G. Ruiz, "Historia de la Constitución «Dei Verbum»", 59.

67 G. RuIz, "Historia de la Constitución «Dei Verbum»", 63.

68 Los peritos: Congar, Rahner, Ratzinger y Semmelroth participaron en la Subcomisión interna de la Comisión Doctrinal de Dei Verbum. Cf. "Tabla de Comisiones que intervinieron en la elaboración de la Const. Dei Verbum”, en L. AlonsoSchöKel y otros, Concilio Vaticano II: Comentarios a la Constitución Dei Verbum sobre la divina revelación (Biblioteca de Autores Cristianos, Madrid 1969) 85.

69 Cf. G. Ruiz, "Historia de la Constitución «Dei Verbum»", 65.

70 Cada esquema posee la numeración original $(28,6,5,5)$. 


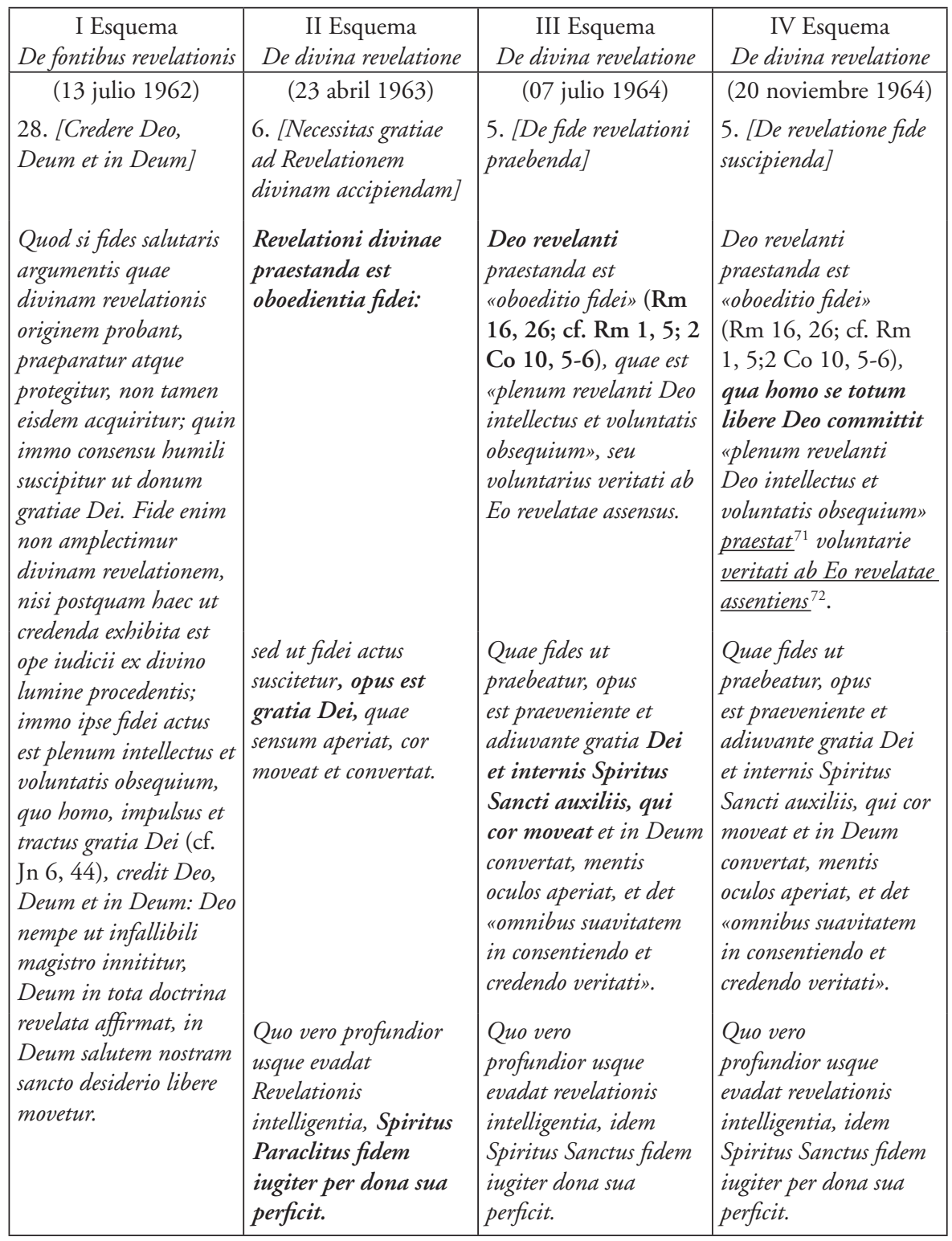

Es notable el modo en que se configuró la teología de la obediencia de la fe, pues en cada esquema pueden distinguirse las diversas formas de pensar la fe, pasando de un lenguaje más imperativo a uno más propositivo.

71 En la versión del texto final, promulgado el 18.11.1965: praestando et.
72 En la versión del texto final: revelationi ab Eo datae assentiendo. 
Comentamos a continuación algunos detalles de esta evolución, por lo que de cada esquema he señalado en negrillas los renglones que trabajaremos. Evidentemente, el criterio de selección de estos pasajes ha sido determinado por el interés original de este trabajo. En el $\mathrm{I}^{\circ} \mathrm{E}$, se aprecia que el documento - podría atreverme a decir- tiene una mentalidad fijada aún en los fundamentos del Vaticano I (que desea vencer al racionalismo), lo que hace difícil una comparación sinóptica con el resto de los esquemas. Sin embargo, podemos destacar que el $\mathrm{I}^{\circ} \mathrm{E}$ comienza asociando -a mi parecer muy peligrosamente- Revelación con ciencia. $\mathrm{Al}$ anteponer a la fe "los argumentos que prueban el origen divino de la revelación” en definitiva, se está poniendo fe y razón en un mismo nivel de intelección, estableciendo la primacía de la fe, que es don divino (donum gratiae Dei). El $\mathrm{II}^{\circ} \mathrm{E}$ elimina lo antepuesto y parte directamente con la afirmación de que ante la Revelación divina el hombre debe presentar la obediencia de la fe (Revelationi divinae praestanda est oboedientia fidei). Hay aquí un paso interesante, ya que no solo se deja de lado la pretensión de verdad científica de la fe, sino que se introduce por primera vez en el Vaticano II el término: obediencia de la fe. Sin incluir todavía un fundamento que explicite su significación, se dice que dicho acto de fe necesita la obra de la gracia de Dios (opus est gratia Dei), sin decir tampoco de forma directa que es el Espíritu Santo su iniciador, pues solo se habla de él al final del número, cuando describe que a través de los dones del Espíritu Paráclito se perfecciona el acto de fe (Spiritus Paraclitus fidem iugiter per dona sua perficit). Pienso que la relevancia de este cambio en la introducción ( del $\mathrm{I}^{\circ} \mathrm{E}$ al $\mathrm{II}^{\circ} \mathrm{E}$ ) radica en que ahora se acentúa -y seguramente también se entiende con mayor claridad- que el acto de fe proviene exclusivamente de Dios, y aun cuando mediante esta fe podemos descubrir en Dios el origen de todo lo que existe, no lo está afirmando en un sentido físico-químico, sino metafísico-existencial. Por tanto, debe cuidarse de no llevar a confusión ambas perspectivas, evitando situar en el mismo horizonte fe y ciencia (a pesar de que la razón sea un sustrato común en el modo de comprensión y aprehensión utilizado por el hombre), no por un tema de superioridad, sino por la necesaria comprensión de los límites de cada una.

Retomando el $\mathrm{I}^{\circ} \mathrm{E}$, debe considerarse como un gran avance la eliminación del último párrafo: credit Deo, Deum et in Deum..., pues se habla de que la infalibilidad del maestro se basa en Dios, un Dios que se afirma en toda la doctrina revelada. Esta aseveración no establece un 
problema en sí misma (aquí no se cuestiona que Dios sea criterio de verdad válido), pues ciertamente quien ha descubierto el rostro de Dios puede hablar de lo que ha conocido y transmitir aquellas cualidades experimentadas y recibidas de él en primera persona. El problema que representa en particular este modo de expresarse es que pareciera que se está poniendo a la Iglesia, especialmente al Magisterio, como primer mediador entre Dios y el hombre, siendo que el acto de Revelaciónrecepción, es un acto que en primera instancia no puede ser mediado por nadie más que Dios mismo -en el Espíritu Santo- que habla directo al corazón de la persona y lo hace en categorías que pueden ser abrazadas con el corazón, la inteligencia y la voluntad humanos (no debemos olvidar que el rol de la Iglesia no es hacer de Dios, sino que debe dejar ser y dejar ver a Dios). Ése es efectivamente "el santo deseo que en Dios se mueve libremente para nuestra salvación" (in Deum salutem nostram sancto desiderio libere movetur).

En cuanto a las incorporaciones hechas al $\mathrm{III}^{\circ} \mathrm{E}$, destacaremos tres sucesos: (1) Ahora el párrafo comienza con Deo revelanti en lugar de Revelationi divinae, lo que a mi juicio acentúa positivamente el carácter personal de la Revelación. Es Dios como ser personal -como sujeto no como objeto-, quien se nos revela. (2) Al fin se establece un marco de comprensión a la obediencia de la fe. No se trata de cualquier obediencia, sino de la postulada por san Pablo, uno de los primeros apóstoles -si no el primero- que presentó esta doctrina, lo que aparece en tres textos: $\mathrm{Rm}$ 16, 26; Rm 1, 5 y 2 Co 10, 5-6:

A aquél que puede consolidaros conforme al Evangelio mío y la predicación de Jesucristo: revelación de un misterio mantenido en secreto durante siglos eternos, pero manifestado al presente, por las Escrituras que lo predicen, por disposición del Dios eterno, dado a conocer a todos los gentiles para obediencia de la fe, a Dios, el único sabio, por Jesucristo, ¡a él la gloria por los siglos de los siglos! (Rm 16, 25-26).

Por él [Jesucristo Señor nuestro] hemos recibido la gracia del apostolado, para obtener la obediencia de la fe a gloria de su nombre entre

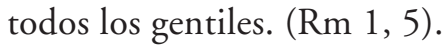

Es importante señalar que en ambos ${ }^{73}$, en el contexto del escrito paulino, la obediencia de la fe tiene un carácter más personal. No es la fe-como

73 No expongo el texto de 2 Co 10, 5-6, porque en él encontramos una estructura y contexto distinto al de Rm. A los corintios les recuerda la necesidad de someter 
influjo externo- la que llama a la obediencia, sino la misma presencia interna de la gracia la que permite en la persona inhabitada por Dios la capacidad de obedecer con su vida, convirtiéndola y orientándola toda hacia él. A partir del reconocimiento y de la aceptación de Dios, el hombre es constituido como testigo/creyente, recibe la gracia, queda fortalecido y es impulsado al apostolado. De este modo, la oboeditio fidei no es impuesta al hombre que cree en Dios (y en Cristo), sino que es constitutiva de su ser religioso (creyente), haciéndose solidaria a él. (3) Se incluye explícitamente la necesidad que tiene el hombre del auxilio interno del Espíritu Santo (et internis Spiritus Sancti auxiliis) quien, en un suave arrebato interior, mueve (moveat) el corazón hacia Dios. Este verbo, que en el I ${ }^{\circ} \mathrm{E}$ aparece como "impulso que fluye de la gracia de Dios" (impulsus et tractus gratia Dei), y en el II ${ }^{\circ} \mathrm{E}$ aparece como obra de la gracia de Dios que "mueve y convierte" (moveat et convertat), aquí se especifica que no solo mueve y convierte, sino que lo hace hacia Dios (qui cor moveat et in Deum convertat). Con este dato del hacia se ilumina aún más el hecho de que sin el Espíritu de Dios, no puede darse una real conversión en el hombre ( $\mu \varepsilon \tau \dot{\alpha} \nu$ ol $\alpha)$, y menos, darse en él la obediencia (i $\pi \alpha x \circ \eta \dot{)}$ de la fe. Finalmente, y en referencia $\mathrm{al} \mathrm{IV}^{\circ} \mathrm{E}$, cabe destacar un atractivo progreso en la propuesta inicial (Deo revelanti praestanda est "oboeditio fidei»), que ahora es complementada por la afirmación: qua homo se totum libere Deo committit. Con este añadido, pienso que el Concilio quiere poner de relieve la necesidad de la cooperación del ser humano en el misterio de la Revelación, es decir, antes de obedecer y ofrecer el homenaje de su entendimiento y voluntad (como continuaba el $\mathrm{III}^{\circ} \mathrm{E}$ ), primero debe unirse libremente a esta Revelación mediante un acto de intelección, que decantará en el rechazo o en la aceptación y entrega de sí al movimiento que el Espíritu Santo está obrando en su interior.

\section{Palabras finales}

La oboeditio fidei puede ser considerada como un proceso de humanización del individuo, pues conlleva una teología que considera al ser humano de forma integral, implicándolo en todas sus dimensiones; lo enaltece en cuanto hijo de Dios, reconociendo su dignidad por sobre el resto de la Creación, rescatando con ello la sublime e inapelable estimación del valor de la vida; y lo exhorta a que, en su status de imagen de

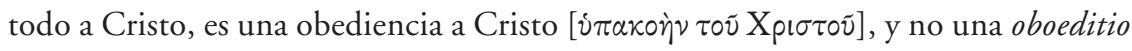
fidei explícitamente. 
Dios, sea responsable y comprometido con su misión; llamándolo como co-creador, a participar del orden universal y divino que rige toda la realidad creada. En este sentido, la oboeditio nos propone el don de la escucha (ob-audire) como clave de interpretación y de actuación humana de la voluntad de Dios; de este modo, la fe se presenta como un medio eficaz no coactivo, para la auscultación de la verdad y para responder al diálogo iniciado por Dios; ofreciéndonos con esto la posibilidad de desplegar libremente nuestra vocación de hijos en el Hijo. En otras palabras, tener a la persona de Jesucristo como primicia de los que creemos y esperamos no es poco, significa comprometernos con la realidad, y a su vez, preguntarnos por la historia que estamos construyendo como individuos, como comunidad cristiana, como Iglesia. La obediencia de la fe a la que llama el Concilio Vaticano, lejos de ser ciega, exige atención a los signos de los tiempos, reflexión, poner los pies en la calle y, por sobre todo, escuchar a los y las que están lejos de experimentar un encuentro vivo con Cristo; a los que sufren en su cuerpo y en su alma, a quienes como Iglesia hemos herido y que hoy pueden ser considerados como invisibles y sin voz. Ésta sería la respuesta más adecuada al diálogo iniciado por Dios, no obstante, a más de cincuenta años de la clausura del Concilio, seguimos encontrando testimonios contradictorios entre dicha invitación y su recepción actual.

Si bien éste es el caminar que cada persona de buena voluntad está invitada a iniciar, recorrer y finalizar, queda abierta aún la reflexión sobre una recuperación del concepto de obediencia de la fe como medio de acceso a la comprensión del misterio de la libertad, que se da en la relación entre Dios y el ser humano (también a partir de la noción agustiniana de libertas), para alcanzar así el desarrollo de una experiencia cristiana íntegra, humanizadora y portadora de sentido. Queda de manifiesto también la necesidad de una vivencia más profunda de la oboeditio fidei a nivel comunitario, para develar, en medio del mundo, la inteligencia del misterio de la libertad que se contiene en el misterio de Dios uno y trino, Dios encarnado.

El Concilio Vaticano II entiende que los tiempos actuales necesitan una teología encarnada, que pueda ser vivida, y a la que se le pueda mirar a los ojos y descubrir su verdad más profunda en ese encuentro personal. Es por esto que, más que instruir sobre la doctrina de la obediencia de la $f e$, lo importante es despojarnos de todo prejuicio de Dios antes de encontrarnos con él. No debe ser la razón la que tenga el primer toque, sino 
el corazón. Esto no significa que el conocimiento de Dios sea un ejercicio irracional, sino que la recepción de su Revelación sea un acto que en primera instancia sea mediado por un Dios que habla directo al corazón del ser humano, y cuyas categorías -al momento de haber penetrado en el alma- deben ser abrazadas por la inteligencia y la voluntad. Con esto, la persona descubrirá su vocación humana, comunitaria y divina, junto con el significado más original de su libertad. 